\title{
Genetic background of coat colour in sheep
}

\author{
Anna Koseniuk, Katarzyna Ropka-Molik, Dominika Rubiś, and Grzegorz Smołucha \\ Department of Animal Genomics and Molecular Biology, National Research \\ Institute of Animal Production, Krakowska 1, 32-083 Balice, Poland
}

Correspondence: Anna Koseniuk (anna.koseniuk@izoo.krakow.pl)

Received: 19 October 2017 - Revised: 13 March 2018 - Accepted: 22 March 2018 - Published: 19 April 2018

\begin{abstract}
The coat colour of animals is an extremely important trait that affects their behaviour and is decisive for survival in the natural environment. In farm animal breeding, as a result of the selection of a certain coat colour type, animals are characterized by a much greater variety of coat types. This makes them an appropriate model in research in this field. A very important aspect of the coat colour types of farm animals is distinguishing between breeds and varieties based on this trait. Furthermore, for the sheep breeds which are kept for skins and wool, coat/skin colour is an important economic trait. Until now the study of coat colour inheritance in sheep proved the dominance of white colour over pigmented/black coat or skin and of black over brown. Due to the current knowledge of the molecular basis of ovine coat colour inheritance, there is no molecular test to distinguish coat colour types in sheep although some are available for other species, such as cattle, dogs, and horses. Understanding the genetic background of variation in one of the most important phenotypic traits in livestock would help to identify new genes which have a great effect on the coat colour type. Considering that coat colour variation is a crucial trait for discriminating between breeds (including sheep), it is important to broaden our knowledge of the genetic background of pigmentation. The results may be used in the future to determine the genetic pattern of a breed. Until now, identified candidate genes that have a significant impact on colour type in mammals mainly code for factors located in melanocytes. The proposed candidate genes code for the melanocortin 1 receptor $(M C I R)$, agouti signaling protein $(A S I P)$, tyrosinase-related protein 1 (TYRPI), microphthalmia-associated transcription factor $M I T F$, and v-kit Hardy-Zuckerman 4 feline sarcoma viral oncogene homologue (KIT). However, there is still no conclusive evidence of established polymorphisms for specific coat colour types in sheep.
\end{abstract}

\section{Introduction}

A large coat colour variation in animals is due to both genetic and environmental backgrounds. In the natural environment, dark/brown coat colours are preferable, whereas for economic purposes, pale coats (i.e. white and yellow) are desirable. Wild species are usually uniform in phenotype and show species-specific colours and patterns. By contrast, domesticated animals have a higher extent of coat colour variation compared to their wild ancestors. Therefore, the domesticated breeds are preferably used as the most suitable animal model for coat colour variation (Cieslak et al., 2011).

The colour diversity results from the presence and biochemical activity of melanocytes, the cells derived from the ectoderm. These cells are specialized in producing melanins - pigments protecting organisms from ultraviolet radiation (Solano, 2014). Melanins are divided into eumelanins (black/brown, pigmented phenotype) and pheomelanins (red/yellow, non-pigmented phenotype). In embryonic development, melanoblasts arise from the neural crest, migrate to the skin within a certain time frame, and then develop into mature forms of melanocytes (Parichy et al., 2006). Within 6 months of embryo development, the number of melanocytes is established (Costin and Hearing, 2007). If the melanoblasts fail to reach certain skin parts, they will lack pigment cells, and this is expressed as white patches (a phenotype leucism). This explains why those parts of an animal's body that are furthest away from the neural crest (i.e. the forehead, legs, belly) are usually white in colour. 
For many years, only the phenotypic classification of breeds has been used. Coat colour phenotypes can be divided into two main types: patterned and non-patterned phenotypes, which are determined by the presence of eumelanin (brown and black) and pheomelanin (red or yellow). The coat colour of breeds was often the only visual trait in the morphological selection for breed identification (Hubbard et al., 2010). Thus, in the classic genetics of mammalian coat colour, the genes/loci names are mostly reflected in their phenotypic effect in the form of skin/coat colour.

Ryder and Land (1974) were among the first to highlight the complexity of the coat colour inheritance process in sheep. Based on an analysis of the proportion of differently coloured sheep performed on Soay, Orkney, and Shetland, these authors suggested that coat colour traits were determined by multiple allelic series within a locus, which can be compared to the agouti gene in mice. Several alleles correspond to variation in coat colour, and it was determined that white $\left(\mathrm{A}_{1}\right.$ allele) was dominant over grey $\left(\mathrm{A}_{2}\right.$ allele). Moreover, A locus is epistatic to the locus $\mathrm{B}$, associated with pigment production and black coat colour $\left(\mathrm{B}_{1}\right)$, and dominant over brown $\left(\mathrm{B}_{2}\right)$ (Ryder and Land, 1974).

The comprehensive study of the inheritance pattern of coat colour in sheep was investigated by Renieri et al. (2008) on lambs which were descended from crosses and backcrosses between seven pigmented rams and 166 full white ewes. It was found that there is no relationship between coat colour (white, black, or brown) and the pigment coat distribution (uniform or regular spotting), on the one hand, and the sex of the individuals on the other. Moreover, it was noticed that the full white phenotype dominated over black and brown and that the black colour is dominant over brown.

A coat/skin colour is an important economic trait in sheep breeding, and in 2013 sheep skin and wool production amounted to over 374 thousand tonnes in Asia and 179 tonnes in Australia and New Zealand combined (http://www.fao.org/faostat/en/\#compare; 15 February 2018). Given the economic importance of the trait as well as its importance for sheep breeders, there is need to broaden our knowledge of the genes which are involved in establishing a particular coat colour pattern. The aim of this review is to summarize findings reported in the literature relating to the genetic basis of coat colour variation in sheep.

\section{Candidate genes}

The most common coat colour loci in farm animals are the A locus (agouti) (Bultman et al., 1992) and the E locus (Extension) (Robbins et al., 1993). It has been established that the number of alleles of the $\mathrm{A}$ and $\mathrm{E}$ loci is variable in different breeds. In cattle, two common $\mathrm{E}$ alleles have been identified $-\mathrm{D}$ (dominant) and e (recessive) - as well as the less frequent allele $\mathrm{E}^{+}$("wild type"). The black phenotype of cattle is usually found in animals possessing the $\mathrm{E}^{D}$ allele, whereas a red coat colour is found in recessive homozygotes (e/e). Interestingly, an $\mathrm{E}^{+}$allele was found to be "neutral", and its presence in genotypes can be expressed with almost any colour (e.g. $E^{D} / \mathrm{E}^{+}$cattle are typically black and $\mathrm{E}^{+} / \mathrm{e}$ cattle are typically red). Moreover, alleles of the agouti locus can be expressed if $\mathrm{E}^{+}$allele is present. The $\mathrm{A}^{+}$allele codes for brown coat colour, whereas recessive homozygotes (aa) are black coloured (Adalsteinsson et al., 1995; Klungland et al., 1995). In horses, so far several dozens of coat colour types and subtypes have been identified, each resulting from several loci/genes (e.g. the champagne locus ( $\mathrm{CH}$ and ch alleles) or cream locus $(\mathrm{C} / \mathrm{C}, \mathrm{Ccr} / \mathrm{C}, \mathrm{Ccr} / \mathrm{Ccr})$ ).

Although classic genetics, which relied on "by eye" classification of coat colour type, was helpful in breeding schemes, it was not sufficient for different reasons. Firstly, different phenotypes can be caused by different alleles of one gene. Secondly, similar phenotypes can be caused by different alleles of many genes (Cieslak et al., 2011). Therefore, in order to define the phenotype, it is very important to determine its genetic complexity. Bennet and Lamoreux (2003) comprehensively reviewed the genetics of pigmentation in mice, pointing out that the most of the genes code for factors that are located in melanocytes. Following Cieslak et al. (2011), the candidate genes might be grouped into four categories depending on their activity in the following processes: (a) development of melanocytes, (b) melanogenesis, (c) pigment transport and transfer, and (d) survival of pigment stem cells.

For the coat colour of mammals, candidate genes have been proposed that code for the melanocortin 1 receptor $(M C 1 R)$, agouti signaling protein $(A S I P)$, tyrosinaserelated protein 1 (TYRP1), microphthalmia-associated transcription factor MITF and v-kit Hardy-Zuckerman 4 feline sarcoma viral oncogene homologue (KIT).

\subsection{The melanocortin 1 receptor $(M C 1 R)$ gene and the agouti signaling protein $(A S I P)$ gene}

According to the classic genetics assumption, the presence of eumelanin or pheomelanin is under the genetic control of Extension and agouti locus. The Extension locus encodes for melanocortin 1 receptor $(M C 1 R)$ a 7-transmembrane $\mathrm{G}$ protein-coupled receptor which is predominantly expressed in melanocytes (Robbins et al., 1993). It has been confirmed that the MC1R gene is about 953 bp long in cattle (Klungland et al., 1995) and $877 \mathrm{bp}$ in horses (Marklund et al., 1996). The ovine MCIR gene is $1000 \mathrm{bp}$ long and consists of one highly polymorphic exon (Fontanesi et al., 2010a).

Some recessive genetic loss-of-function variants in the $M C 1 R$ gene are responsible for the red hair colour phenotype in humans (red hair, fair skin) and increase the risk of developing cutaneous melanoma (Valverde et al., 1995). The $M C 1 R$ polymorphism has been used to detect hybrids in wild boars (Sus scrofa scrofa) and domestic pigs (Sus scrofa domestica), which was not possible with the use of the mi- 
tochondrial DNA polymorphism (Fajardo et al., 2008). A unique $M C 1 R$ allele $\left(\mathrm{E}^{+}\right)$associated with the wild-type coat colour of European wild boar has not been found in any of the domestic pig breeds (Fajardo et al., 2008; Koutsogiannouli et al., 2010). The functional and non-functional mutations of the $M C 1 R$ gene have been described for cattle (Klungland et al., 1995), pigs (Kijas et al., 1998), horses (Marklund et al., 1996), and sheep (Fontanesi et al., 2010a) and have an effect on dominant or partially dominant black or dark phenotypes or on recessive or partially recessive red, yellow, or pale coats.

The agouti locus encodes the agouti signalling protein $(A S I P)$, a paracrine molecule. The $M C 1 R$ and $A S I P$ genes reveal the epistatic interaction. A binding of $M C 1 R$ with the $\alpha$ melanocyte-stimulating hormone ( $\alpha \mathrm{MSH})$ on the surface of the melanocyte membrane stimulates eumelanin production. An alternative binding with ASIP causes a synthesis of pheomelanins (Lu et al., 1994; Ollmann et al., 1998). It is believed that a black pigmentation is induced by dominant Extension alleles $\left(\mathrm{E}^{\mathrm{D}}\right)$, whereas recessive alleles cause the synthesis of pheomelanin. It is worth noting that the expression of the mutated agouti alleles is dependent on the presence of wild-type Extension alleles $\left(\mathrm{E}^{+}\right)$. The dominant agouti alleles determine pheomelanin phenotypes, whereas recessive alleles cause black coat colour (Bennett and Lamoreux, 2003). This last is of special interest to breeders since it is impossible to distinguish by eye a sheep with recessive alleles causing black fur colour. This is the reason why black lambs are sometimes born in flocks of white sheep (Våge et al., 2003).

In sheep, classic genetic studies have identified a twoallele series at the Extension locus: one is expressed in the dominant black phenotype allele $\mathrm{E}^{\mathrm{D}}$ (Våge et al., 1999) and the other in the wild type $\left(\mathrm{E}^{+}\right)$, which de facto has the effect of ASIP alleles (described by Fontanesi et al., 2010a). Våge et al. (2003) mapped MC1R to ovine chromosome 14 and identified the two missense mutations, i.e. Met $>$ Lys mutation at position 73 and the Asp $>$ Asn mutation at position 121 , which results in a dominant black effect $\left(\mathrm{E}^{\mathrm{D}}\right.$ allele) (Våge et al., 1999, 2003). The mutation in the $\mathrm{E}^{+}$locus (c.199C > T, p.R67C) resulted in a red or brown spotted sheep coat (Fontanesi et al., 2010a).

The ovine agouti locus has been mapped to chromosome 13, containing the sequence for the agouti signaling protein (Beraldi et al., 2006). The ASIP variations include a nine base pair deletion (D9) g.10-19delAGCCGCCTC, a five base pair deletion (D5) g.100-105delAGGAA, and point mutations: $\mathrm{g} .5051 \mathrm{G}>\mathrm{C}$ and g.5172T $>\mathrm{A}$. The D5 and g.5172T $>$ A mutations change the function of the ASIP protein. In homozygotes for one or both of these mutations, the recessive black phenotype is expressed (Norris and Whan, 2008; Gratten et al., 2010).

The recent studies using CRISP/Cas9 technology allowed us to confirmed that the ASIP gene is strongly related to the coat colour pattern in sheep (Zhang et al., 2017). Gene edi- tion by the CRISP/Cas9 method was applied to lambs displaying a variety of coat colour patterns. Furthermore, the authors showed that a variable number of ASIP gene copies was involved in the formation of colour patterns, which clearly indicates a critical role of this gene in coat colour determination (Zhang et al., 2017).

\subsection{The tyrosinase-related protein 1 (TYRP1) gene}

In addition to Extension and agouti loci, the best-known colour genes in the sheep genome are the tyrosinaserelated protein 1 (TYRP1), the v-kit Hardy-Zuckerman 4 feline sarcoma viral oncogene homologue $(K I T)$, and the microphthalmia-associated transcription factor $(M I T F)$ (García-Gámez et al., 2011; Kijas et al., 2012; Li et al., 2014).

The tyrosinase-related protein 1 (TYRPl) is a membranebound protein identified in melanocytes and retinal epithelium. In mice, the gene for TYRP 1 is characterized by the most phenotypic alleles of all known colour loci (Bennet and Lamoreux, 2003). Moreover, some mutations in the gene for TYRP 1 are correlated with oculocutaneous albinism type 1 in humans and albinism in mice (Jackson and Bennett, 1990; Boissy et al., 1996). During melanogenesis, the TYRP1 protein converts a precursor of eumelanin and pheomelanin into eumelanin, which results in dark-coloured tissue (Bennet and Lamoreux, 2003).

There had not been any evidence for the connection between the TYRPI gene and coat colour in sheep until the study on Soay sheep conducted by Gratten et al. (2007). The authors found that the ovine BMS678 microsatellite locus (bovine sequence homologue) co-segregates with the TYRPI sequence, which is located on ovine chromosome 2. According to Gratten et al. (2007), the $869 \mathrm{G}>\mathrm{T}$ functional mutation causes a change of cysteine (Cys) into phenylalanine (Phe) and results in the presence of either a dominant dark or a recessive light allele.

\subsection{The microphthalmia-associated transcription factor MITF and the v-kit Hardy-Zuckerman 4 feline sarcoma viral oncogene homologue $(K I T)$}

The KIT gene plays a crucial role in the migration of melanocyte precursors from the neural crest to the skin (Lamoureux, 1999). The abnormity of this migration results in piebaldism, i.e. the presence of white spots on coloured body regions. In cattle, classic genetics has indicated the spotting (S) locus that has a significant effect on cattle piebaldism. In this locus, four alleles have been determined: $\mathrm{S}^{+}$- wild type, non-spotted; $\mathrm{S}^{\mathrm{H}}$ - Hereford pattern, solid brown except for the head and abdomen, which are solid white; $S^{P}$ - Pinzgauer pattern or lineback, white back and abdomen with brown head, sides and legs. In contrast to classic genetics, genome-wide research has indicated a polygenic background of piebaldism. Surveys conducted on cattle to 
date have suggested that the KIT, MITF, and PAX5 genes contribute strongly to piebald phenotypes (Fontanesi et al., 2010b, c; Hayes et al., 2010).

Han et al. (2015) analysed the presumed relation and interaction between the ovine KIT and MITF gene expression and whether it affects the colour of sheep wool. The MITF gene codes for a protein microphthalmia-associated transcription factor, the most obvious function of which is the development of melanocytes; the MITF expression is correlated with the pigment accumulation in melanocytes (Steingrímsson et al., 2004). Causative mutations in MITF are mostly recognized to be involved in metabolic disorders in melanocytes, affecting the pigment content of the skin, hair, and eyes. Moreover, in eyes, the microphthalmia-associated transcription factor plays a role in the development of retinal pigment epithelial cells (Zhang et al., 2012).

In the research conducted by Han et al. (2015) on Tibetan sheep, both the MITF mRNA and the protein level were significantly higher in both solid-black skin tissue and blackspot tissue compared to white-colour tissue. In addition, neither KIT mRNA nor KIT protein expression differed between white and black skin tissue. The results indicate the essential role of MITF expression for pigment accumulation in sheep wool (Han et al., 2015).

\section{High-throughput genetic techniques - next-generation sequencing and microarray methods}

Since the introduction of high-throughput genetic techniques, some additional genes as well as new factors that have an impact on pigmentation have been identified. The greatest advantage of the high-throughput sequencing methods is the possibility of obtaining a great deal of data of entire genomes. It gives the possibility of obtaining complex information about specific processes and of identifying the new genetic basis of important phenotypic traits such as coat colour in sheep.

The first time a microarray study on the pigmentation of sheep was conducted was in Peñagaricano et al. (2012). Gene expression was studied on black-spotted as well as solidwhite skin samples of five Corriedale sheep. The highest expression was indicated by, among others, C-FOS and CREB (cAMP response element binding gene). Both genes are involved in melanogenesis: C-FOS is a genetic factor stimulating melanin synthesis as the response to ultraviolet (UV) light (Gordon et al., 1992), and CREB is a transcription factor of numerous genes including MITF (Schallreuter et al., 2007). Surprisingly, Peñagaricano et al. (2012) did not identify a significant difference in the expression of ASIP for black or white skin samples. The results contrast with those of Norris and Whan (2008) and Fontanesi et al. (2011), who indicated the duplication of the functional ASIP region as a cause of the white phenotype. The other conclusion of the re- search is that ovine $M C 1 R$ was not expressed in spotted skin samples. This might exclude this gene as having an effect on spotted phenotype formation.

Fan et al. (2013) analysed skin transcriptomes from white and black merino sheep. The authors obtained over 100 million raw reads from both skin colour types using the Illumina sequencing technology. According to data analysis, they determined 37768 known genes, of which 2235 were differently expressed in black vs. white sheep. Among the differently expressed coat colour genes, TYRPI was the one that had the most significant expression differences between the two groups of sheep. This gene, as well as TYR, MLPH, $M A T P$, and $S i$, was more highly expressed in black sheep skin. Moreover, TYRP1, TYR, MLPH, and MATP code for proteins involved in the pigment regulation of mammalian melanocytes. The $M L P H$ gene codes for melanophilin. The $M L P H$ gene polymorphism is associated with the "diluted" phenotype of many animal species, including cats (Ishida et al., 2006), dogs (Philipp et al., 2005), and rabbits (Lehner et al., 2013). The MATP gene encodes for the Membrane Associated Transporter Protein (MATP), also known as the solute carrier family 45 member 2 (SLC45A2). The protein plays a significant role in the processing and intracellular trafficking of tyrosinase and other proteins of melanosomes (Costin et al., 2003).

The microarray study conducted on Finnsheep ( $\mathrm{Li}$ et al., 2014) indicates a significance effect of SNP s66432.1 in ASIP on white/non-white-coloured wool. The homozygotes (A/A) are found in $96 \%$ of white-coloured Finnsheep, whereas they are found in only $2 \%$ of black animals in the non-white Finnsheep.

According to the results of Fan et al. (2013), there were upregulated genes encoding transcription factors regulating mRNA expression (e.g. MITF) in white skin tissue, whereas in black skin tissue several novel genes were detected. Two of these were expressed exclusively in black sheep. The authors suggest that these genes may be associated with a different transcription of melanocyte-specific genes, supporting pigment synthesis and a dark phenotype.

Although some research on the genetic basis of wool colour has been conducted, the complexity of the issue remains. Identifying the genetic factors of coat colour in sheep is pivotal for improving the efficiency of artificial selection for preferable coat colour (or pattern) as well as for studying the evolutionary changes regarding the phenotypic variation in farm and wild animals.

Data availability. Data are available from the corresponding author upon request. 
Author contributions. All co-authors contributed to the preparation of the manuscript. Specifically, AK prepared Sect. 2 of the manuscript, with contribution from GS, KRM prepared Sect. 3 of the manuscript with contribution from DR, and AK drafted the entire manuscript.

Competing interests. The authors declare that they have no conflict of interest.

Acknowledgements. This study was supported by the National Research and Development Center (Poland) under the Strategic Research and Development Program "Environment, Agriculture and Forestry" - BIOSTRATEG, decision number BIOSTRATEG2/297267/14/NCBR/2016.

Edited by: Steffen Maak

Reviewed by: two anonymous referees

\section{References}

Adalsteinsson, S., Bjarnadottir, S., Vage, D. I., Jonmundsson, and Brown, J. V.: coat color in icelandic cattle produced by the loci Extension and Agouti, J. Hered., 86, 395-398, 1995.

Bennett, D. C. and Lamoreux, M. L.: The color loci of mice-a genetic century, Pigment Cell Res., 16, 333-344, 2003.

Beraldi, D., McRae, A. F., Gratten, J., Slate, J., Visscher, P. M., Pemberton, and J. M.: Development of a linkage map and mapping of phenotypic polymorphisms in a free-living population of soay sheep (Ovis aries), Genetics, 173, 1521-1537, 2006.

Boissy, R. E., Zhao, H., Oetting, W. S., Austin, L. M., Wildenberg, S. C., Boissy, Y. L., Zhao, Y., Sturm, R. A., Hearing, V. J., King, R. A., and Nordlund, J. J.: Mutation in and lack of expression of tyrosinase-related protein-1 (TRP-1) in melanocytes from an individual with brown oculocutaneous albinism: a new subtype of albinism classified as "OCA3", Am. J. Hum. Genet., 58, 11451156, 1996.

Bultman, S. J., Michaud, E. J., and Woychik, R. P.: Molecular characterization of the mouse agouti locus, Cell, 71, 1195-1204, 1992.

Cieslak, M., Reissmann, M., Hofreiter, M., and Ludwig, A.: Colours of domestication, Biol. Rev., 86, 885-899, 2011.

Costin, G. E. and Hearing, V. J.: Human skin pigmentation: melanocytes modulate skin color in response to stress, FASEB J., 21, 976-994, 2007.

Costin, G. E., Valencia, J. C., Vieira, W. D., Lamoreux, M. L., and Hearing, V. J.: Tyrosinase processing and intracellular trafficking is disrupted in mouse primary melanocytes carrying the underwhite (uw) mutation. A model for oculocutaneous albinism (OCA) type 4, J. Cell Sci., 116, 3203-3212, 2003.

Fajardo, V., González, I., Martín, I., Rojas, M., Hernández, P. E., García, T., and Martin R.: Differentiation of European wild boar (Sus scrofa scrofa) and domestic swine (Sus scrofa domestica) meats by PCR analysis targeting the mitochondrial D-loop and the nuclear melanocortin receptor 1 (MC1R) genes, Meat Sci., 78, 314-322, 2008.
Fan, R., Xie, J., Bai, J., Wang, H., Tian, X., Bai, R., Jia, X., Yang, L., Song, Y., Herrid, M., Gao, W., He, X., Yao, J., Smith, G. W., and Dong, C.: Skin transcriptome profiles associated with coat color in sheep, BMC Genomics, 14, 389, https://doi.org/10.1186/14712164-14-389, 2013.

Fontanesi, L., Beretti, F., Riggio, V., Dall'Olio, S., Calascibetta, D., Russo, V., and Portolano, B.: Sequence characterization of the melanocortin 1 receptor (MC1R) gene in sheep with different coat colours and identification of the putative e allele at the ovine Extension locus, Small Rumin. Res., 91, 200-207, 2010a.

Fontanesi, L., Scotti, E., and Russo, V.: Analysis of SNPs in the KIT gene of cattle with different coat colour patterns and perspectives to use these markers for breed traceability and authentication of beef and dairy products, Ital. J. Anim. Sci., 9, 217-221, 2010b.

Fontanesi, L., Tazzoli, M., Russo, V., and Beever, J.: Genetic heterogeneity at the bovine KIT gene in cattle breeds carrying different putative alleles at the spotting locus, Anim. Genet., 41, 295-303, 2010c.

Fontanesi, L., Dall' Olio, S., Beretti, F., Portolano, B., and Russo, V.: Coat colours in the Massese sheep breed are associated with mutations in the agouti signalling protein (ASIP) and melanocortin 1 receptor (MC1R) genes, Animal, 5, 8-17, 2011.

García-Gámez, E., Reverter, A., Whan, V., McWilliam, S. M., and Arranz, J. J.: International Sheep Genomics Consortium, et al. Using regulatory and epistatic networks to extend the findings of a genome scan: Identifying the gene drivers of pigmentation in Merino sheep, PLoS One, 6, e21158, https://doi.org/10.1371/journal.pone.0021158, 2011.

Gordon, L., Peacocke, M., and Gilchrest, B. A.: Induction of c-fos but not c-myc in S-91 cells by melanization signals, J. Dermatol. Sci., 3, 35-41, 1992.

Gratten, J., Pilkington, J. G., Brown, E. A., Beraldi, D., Pemberton, J. M., and Slate, J.: The genetic basis of recessive self-colour pattern in a wild sheep population, Heredity, 104, 206-214, 2004

Gratten, J., Pilkington, J. G., Brown, E. A., Beraldi, D., Pemberton, J. M., and Slate, J.: The genetic basis of recessive self-colour pattern in a wild sheep population, Heredity, 104, 206-214, 2010.

Gratten, J., Beraldi, D., Lowder, B. V., McRae, A. F., Visscher, P. M., Pemberton, J. M., and Slate, J.: Compelling evidence that a single nucleotide substitution in TYRP1 is responsible for coatcolour polymorphism in a free-living population of Soay sheep, P. Roy. Soc. Lond. B, 274, 619-626, 2007.

Han, J. L., Yang, M., Guo, T. T., Yue, Y. J., Liu, J. B., Niu, C. E., Wang, C. F., and Yang, B. H.: Molecular characterization of two candidate genes associated with coat color in Tibetan sheep (Ovis arise), J. Integr. Agric., 14, 1390-1397, 2015.

Hayes, B. J., Pryce, J., Chamberlain, A. J., Bowman, P. J., and Goddard, M. E.: Genetic architecture of complex traits and accuracy of genomic prediction: coat colour, milk-fat percentage, and type in Holstein cattle as contrasting model traits, PLoS Genetics, 6, e1001139, https://doi.org/10.1371/journal.pgen.1001139, 2010.

Hubbard, J. K., Uy, J. A. C., Hauber, M. E., Hoekstra, H. E., and Safran, R. J.: Vertebrate pigmentation: from underlying genes to adaptive function, Trends Genet., 26, 231-239, 2010.

Ishida, Y., David, V. A., Eizirik, E., Schäffer, A. A., Neelam, B. A., Roelke, M. E., Hannah, S. S., O'Brien, S. J., and MenottiRaymond, M.: A homozygous single-base deletion in MLPH causes the dilute coat color phenotype in the domestic cat, $\mathrm{Ge}$ nomics, 88, 698-705, 2006. 
Jackson, I. J. and Bennett, D. C.: Identification of the albino mutation of mouse tyrosinase by analysis of an in vitro revertant, $\mathrm{P}$. Natl. Acad. Sci. USA, 87, 7010-7014, 1990.

Kijas, J. M. H., Wales, R., Törnsten, A., Chardon, P., Moller, M., and Andersson, L.: Melanocortin receptor 1 (MC1R) mutations and coat color in pigs, Genetics, 150, 1177-1785, 1998.

Kijas, J. W., Lenstra, J. A., Hayes, B., Boitard, S., Neto, L. R., Cristobal, M. S., Servin, B., McCulloch, R., Whan, V., Gietzen, K., Paiva, S., Barendse, W., Ciani, E., Raadsma, H., McEwan, J., Dalrymple, B., and other members of the International Sheep Genomics Consortium: Genome-wide analysis of the world's sheep breeds reveals high levels of historic mixture and strong recent selection, PLoS Biol., 10, e1001258, https://doi.org/10.1371/journal.pbio.1001258, 2012.

Klungland, H., Vage, D. I., Gomez-Raya, L., Adalsteinsson, S., and Lien, S.: The role of melanocyte-stimulating hormone (MSH) receptor in bovine coat color determination, Mamm. Genome, 6, 636-639, 1995.

Koutsogiannouli, E. A., Moutou, K. A., Sarafidou, T., Stamatis, C., and Mamuris, Z.: Detection of hybrids between wild boars (Sus scrofa scrofa) and domestic pigs (Sus scrofa f. domestica) in Greece, using the PCR-RFLP method on melanocortin-1 receptor (MC1R) mutations, Mamm. Biol., 75, 69-73, 2010.

Lamoreux, M. L.: Strain-specific white-spotting patterns in laboratory mice, Pigment Cell. Res., 12, 383-390, 1999.

Lehner, S., Gähle, M., Dierks, C., Stelter, R., Gerber, J., and Brehm, R.: Two-Exon Skipping within MLPH Is Associated with Coat Color Dilution in Rabbits, PloS One, 8, e84525, https://doi.org/10.1371/journal.pone.0084525, 2013.

Li, M. H., Tiirikka, T., and Kantanen, J.: A genome-wide scan study identifies a single nucleotide substitution in ASIP associated with white versus non-white coat-colour variation in sheep (Ovis aries), Heredity, 112, 122-131, 2014.

Lu, D., Willard, D., Patel, I. R., Kadwell, S., Overton, L., Kost, T., Luther, M., Chen, W., Woychik, R. P., Wilkison, W. O., and Cone, R. D.: Agouti protein is an antagonist of the melanocytestimulating-hormone receptor, Nature, 371, 799-802, 1994.

Marklund, L., Moller, M. J., Sandberg, K., and Andersson, L.: A missense mutation in the gene for melanocyte-stimulating hormone receptor (MC1R) is associated with the chestnut coat color in horses, Mamm. Genome, 7, 895-899, 1996.

Norris, B. J. and Whan, V. A.: A gene duplication affecting expression of the ovine ASIP gene is responsible for white and black sheep, Genome Res., 18, 1282-1293, 2008.

Ollmann, M. M., Lamoreux, M. L., Wilson, B. D., and Barsh, G. S.: Interaction of Agouti protein with the melanocortin 1 receptor in vitro and in vivo, Genes Dev., 12, 316-330, 1998.

Parichy, D. M., Reedy, M. V., and Erickson, C. A.: Regulation of melanoblast migration and differentation. The Pigmentary System and its disorders, 2nd Edn., Oxford University Press, Oxford, 108-127, 2006.
Peñagaricano, F., Zorrilla, P., Naya, H., Robello, C., and Urioste, J. I.: Gene expression analysis identifies new candidate genes associated with the development of black skin spots in Corriedale sheep, J. Appl. Genet., 53, 99-106, 2012.

Philipp, U., Hamann, H., Mecklenburg, L., Nishino, S., Mignot, E., Schmutz, S. M., and Tosso, L.: Polymorphisms within the canine MLPH gene are associated with dilute coat color in dogs, BMC Genetics, 15, 1-15, 2005.

Renieri, C., Valbonesi, A., La Manna, V., Antonini, M., and Lauvergne, J. J.: Inheritance of coat colour in Merino sheep, Small Ruminant Res., 74, 23-29, 2008.

Robbins, L. S., Nadeau, J. H., Johnson, K. R., Kelly, M. A., RoselliRehfuss, L., Baack, E., Mountjoy, K. G., and Cone, R. D.: Pigmentation phenotypes of variant extension locus alleles result from point mutations that alter MSH receptor function, Cell, 72, 827-834, 1993.

Ryder, M. L. and Land, R. B.: Coat colour inheritance in Soay, Orkney and Shetland sheep, J. Zool., 173, 477-485, 1974.

Schallreuter, K. U., Kothari, S., Chavan, B., and Spencer, J. D.: Regulation of melanogenesis - controversies and new concepts, Ex. Dermatol., 17, 395-404, 2007.

Solano, F.: Melanins: Skin Pigments and Much More-Types, Structural Models, Biological Functions and Formation Routes, New J. Sci., 28, 498276, https://doi.org/10.1155/2014/498276, 2014.

Steingrímsson, E., Copeland, N. G., and Jenkins, N. A.: Melanocytes and the Microphthalmia Transcription Factor Network, Annu. Rev. Genet., 38, 365-411, 2004.

Våge, D. I., Klungland, H., Dongsi, L., and Cone, R. D.: Molecular and pharmacological characterization of dominant black coat color in sheep, Mamm. Genome, 10, 39-43, 1999.

Våge, D. I., Fleet, M. R., Ponz, R., Olsen, R. T., Monteagudo, L. V., Tejedor, M. T., Arruga, M. V., Gagliardi, R., Postiglioni, A., Nattrass, G. S., and Klungland, H.: Mapping and characterization of the dominant black colour locus in sheep, Pigment Cell Res., 16, 693-697, 2003.

Valverde, P., Healy, E., Jackson, I., Rees, J. L., and Thody, A. J.: Variants of the melanocyte-stimulating hormone receptor gene are associated with red hair and fair skin in humans, Nat. Genet., 11, 328-330, 1995.

Zhang, H., Luo, H., Chen, H., Mei, L., He, C., Jiang, L., Li, J. D., and Feng, Y.: Functional analysis of MITF gene mutations associated with Waardenburg syndrome type 2, FEBS Lett., 586, 4126-4131, 2012.

Zhang, X., Li, W., Liu, C., Peng, X., Lin, J., He, S., Li, X., Han, B., Zhang, N., Wu, Y., Chen, L., Wang, L., MaYila., Huang, J., and Liu, M.: Alteration of sheep coat color pattern by disruption of ASIP gene via CRISPR Cas9, Sci. Rep., 15, 8149, https://doi.org/10.1038/s41598-017-08636-0, 2017. 